\title{
Performance Evaluation of the Earth Gravitational Model 2008 (EGM2008) - A Case Study
}

\author{
M. S. Peprah ${ }^{1}$, Y. Y. Ziggah ${ }^{1}$, I. Yakubu ${ }^{1}$ \\ ${ }^{1}$ Department of Geomatic Engineering, University of Mines and Technology, Tarkwa, \\ Ghana.
}

*Corresponding authors email: yyziggah@umat.edu.gh; mspeprah@ st.umat.edu.gh

DOI: http://dx.doi.org/10.4314/sajg.v6i1.4

\begin{abstract}
Ghana's local geodetic reference network which is based on the War Office 1926 ellipsoid was established using astro-geodetic observations during the British Colonial era with data in latitude, longitude and orthometric height $(\varphi, \lambda, H)$ without the existence of ellipsoidal height. The Global Positioning System (GPS) observations which is an example of the Global Navigation Satellite System (GNSS) is being referenced to the World Geodetic System 1984 (WGS84) ellipsoid with data in latitude, longitude and ellipsoidal heights $(\varphi, \lambda, h)$. This prevalent situation makes it difficult to apply standard forward transformation equation for direct conversion of ellipsoidal heights $(h)$ which is global to a practical height $(H)$ within Ghana local geodetic reference network. In order to overcome such a challenge, many researchers resort to various methods of determining the geoidal undulations for a local and national geodetic network and improving the recent New Earth Gravitational Model accuracies and its performances. This present study therefore seeks to evaluate such method of estimating geoidal heights using the Earth Gravitational Model 2008 (EGM08) in a part of the University of Mines and Technology, UMaT, Tarkwa. The estimated geoid heights obtained by the EGM08 model were compared with 328 discrete geometrical heights from co-located GPS and Total station orthometric heights of the University Primary Levelling Networks. The methods applied include estimating the geoidal heights using the EGM08 model, a geometric method and a polynomial mathematical model for improving the estimated EGM08 geoid heights values. The statistics of the differences between derived geoid heights by the geometric approach and corresponding geoid heights
\end{abstract}


obtained from the geoid model (EGM08) suggests that, the EGM08 model is most suitable at this moment. The RMSE, Mean Error, and the Standard deviation of their geoidal height differences are $0.120825 \mathrm{~m}, 2.18823 \mathrm{~m}$, and $3.47678 \mathrm{~m}$, which is better in the area of interest. The study concluded that, the recent geoid model can be applied in UMaT and the polynomial mathematical model is the best model for modelling EGM08 geoid heights values for a local geoid model.

Keywords: GPS/levelling, Earth Gravitational Model, Polynomial mathematical model, Geoid undulations

\section{Introduction}

Over the years, one of the most interesting and challenging tasks in the field of geodetic surveying is the accurate determination of orthometric heights from GNSS, in particular GPS measurements (Al-Ghamdi and Dawod, 2013, Lee et al., 2012) for a local geodetic datum. This poses a challenge for high order engineering works such as engineering surveys or 3D coordinate transformation and mapping (Featherstone et al., 2001; Fotopoulos, 2003). This has therefore drawn the attention of many researchers in the area of orthometric height determination (Ulotu, 2009). Moreover, converting the GPS ellipsoidal height to a physical meaning require the determination of orthometric height and the geoid undulation of the area (Shen and Han, 2013; Dumrongchai et al., 2012). The EGM96 and EGM08 are some of the models used to calculate the geoid undulation of an area to determine the orthometric height from GPS measurements (Do, 2011). The original technique that was used to compute the geoid undulation was the Stokes' integral (Heiskanen and Moritz, 1967).

In line of the above, the EGM08 method has been the most widely used for height conversion in some countries and to a relatively high degree of accuracy. The EGM08 is good enough for geodetic applications like determining the topographic heights of points on the globe that require the geoid which approximates Mean Sea Level (MSL) as the datum/reference surface (Yilmaz et al., 2010; Abeho et al., 2014). The EGM08 was preceded by EGM96 which had a lower degree of accuracy (Pavlis et al., 2008). In this modern era, EGM08 is capable of obtaining a sufficiently accurate model of the gravity field over the surface of the earth (Kotsakis et al., 2009; Kotsakis and Sideris, 1999). This is a 
great achievement in the fields of geodesy and geophysics since we can obtain heights with physical meaning without necessarily carrying out the tedious and time-consuming procedures of obtaining these heights by geometric or trigonometric levelling (Hirt, et al., 2011, Gruber et al., 2011). The EGM08 derived geoid heights can reach the accuracy of regional or local geoid models after modelling the differences between the GPS/levelling geoid heights and EGM08 derived geoid heights at identified control points (Dawod, 2008; Dawod et al., 2010; Soycan, 2014).

In view of the above, several researchers were motivated to come up with both empirical and geometric approach for the improvement of the earth gravitational model and also to develop their own regional and national geoid (Chandler and Merry, 2010; Kuroishi et al., 2002; Roman et al., 2009; Toth et al., 2000). Some of the global geoid model that have been used for geoid modelling include OSU91A (Rapp et al., 1991), EGM96 (Lemoine et al., 1998), GGM02C (Tapley et al., 2005, EGM08 (Pavlis et al., 2008), AGP2003 (Merry et al., 2005), AGP2006 (Parker et al., 2007), TZG07 (Olliver, 2007), GEM-T3 (Lerch et al., 1994), GRIM4-C2 (Rapp and Wang, 1993), and TG09 (Erol and Erol, 2012). Several mathematical models have been proposed over the decades to improve the working efficiency of the EGM08. Some of the mathematical models proposed include Stokes's formula (Featherstone, 2012), Least Squares Collocation (Lee et al., 2013), and polynomial methods (Soycan, 2014; Erol, 2011). This is because the global geopotential models (GGMs) prompt the long wavelength components of the Earth's gravity field very well (Daho et al., 2008; Krynski and Lyszkowicz, 2006). They do not only provide a basis for the gravity field when emergent high-precision geoid models, but they are also momentous as reference surfaces for conniving local geoids (Bae et al., 2011; Dawod et al., 2010). Countries that are yet to develop geoid models have been using GGMs for the calculation of geoid heights and gravity anomalies through spherical harmonic analysis (Lee et al., 2008).

An accurate geoid model is essential for determining orthometric heights using the GNSS technology, which is being accepted globally for geodetic purposes (Fotopoulus et al., 1999). Many researchers have improved the working efficiency of EGM08 with the polynomial mathematical model. Although several mathematical models exist for the modelling of the EGM08 geoid heights, the application of polynomial approach was adopted in this present study to improve the working efficiency of the EGM08 in the study area. The motivation for using the polynomial model was based on its simplicity in application and promising results reported in literature (Erol, 2011; Al-Kragy et al., 2014; Dawod et al., 
2010; Dawod, 2008; Soycan, 2014). In addition, it can be used for GPS/levelling at the local scale and significant for local geoid modelling (Dawod, 2008). Hence, the polynomial approach provides a provides a promising evidence for its future use in various geodetic applications (Erol, 2011).

The present study considered the University of Mines and Technology (UMaT) campus as a case of application of the EGM08. This is because the local geodetic datum of the University of Mines and Technology (UMaT) is non-geocentric with data in latitude, longitude and orthometric height with geoid model. Therefore, in order to convert the GPS ellipsoidal height for practical engineering applications, there is the need to determine the geoidal undulation of the co-located ellipsoidal and orthometric heights in the local War Office 1926 ellipsoid and World Geodetic System (WGS84) datums. In so doing, the accuracy of the obtained geoidal undulation from the EGM08 can be accessed with those attained from GPS/levelling measurement. Moreover, to the best of our knowledge, the applicability and performance assessment of EGM08 for height conversion in Ghana has not been evaluated. Therefore, this study evaluated and tested the accuracy of using the EGM08 as a method for height conversion within the University of Mines and Technology (UMaT) campus and improving its accuracies by a polynomial mathematical model. Therefore, this study constitutes a good foundation for future research into EGM08 in Ghana.

\section{Study Area and Data Source}

The study area (Figure 1) is located in the mining town of Tarkwa which happens to be the administrative capital of the Tarkwa Nsuaem Municipal Assembly. It is located in the southwest of Ghana with geographical coordinates between longitudes $1^{\circ} 59^{\prime} 00^{\prime \prime} \mathrm{W}$ and latitude $5^{\circ} 18^{\prime} 00^{\prime \prime} \mathrm{N}$ and is $78 \mathrm{~m}$ above mean sea level. It is about $85 \mathrm{~km}$ from Takoradi, which is the regional capital, $233 \mathrm{~km}$ from Kumasi and about $317 \mathrm{~km}$ from Accra (Ziggah, 2012). The topography is generally described as remarkable series of ridges and valleys. The ridges are formed by the Banket and Tarkwa Phyllites whereas upper quartzite and Huni Sandstone are present in the valleys. Surface gradients of the ridges are generally very close to the Banket and Tarkwa Phyllites. The University and its environs generally lie within the mountain ranges covered by thick forest interjected by undulating terrain with few scarps. The type of coordinate system used in the study area is the Ghana projected grid derived from the Transverse Mercator $1^{\circ} \mathrm{NW}$ and the (WGS84) (UTM Zone 30N). The datum of 
the University of Mines and Technology are the World Geodetic System 1984 (WGS84); War Office Ellipsoid; Leigon; and the geoid which approximates the Mean Sea Level (MSL). The projection of the University of Mines and Technology is the Transverse Mercator (Ziggah, 2014; (Seidu, 2004)). The study area has a South-western Equatorial climate with seasons influenced by the moist South-West Monsoon winds from the Atlantic Ocean and the North-East Trade Winds. The mean rainfall is approximately $1500 \mathrm{~mm}$ with peaks of more than $1700 \mathrm{~mm}$ in June and October. Between November and February, the rainfall pattern decreases to between $20 \mathrm{~mm}$ to $90 \mathrm{~mm}$ (Forson, 2006). The mean annual temperature is approximately $25{ }^{\circ} \mathrm{C}$ with small daily temperature variations. Relative humidity varies from $61 \%$ in January to a maximum of $80 \%$ in August and September (Ziggah, 2012).

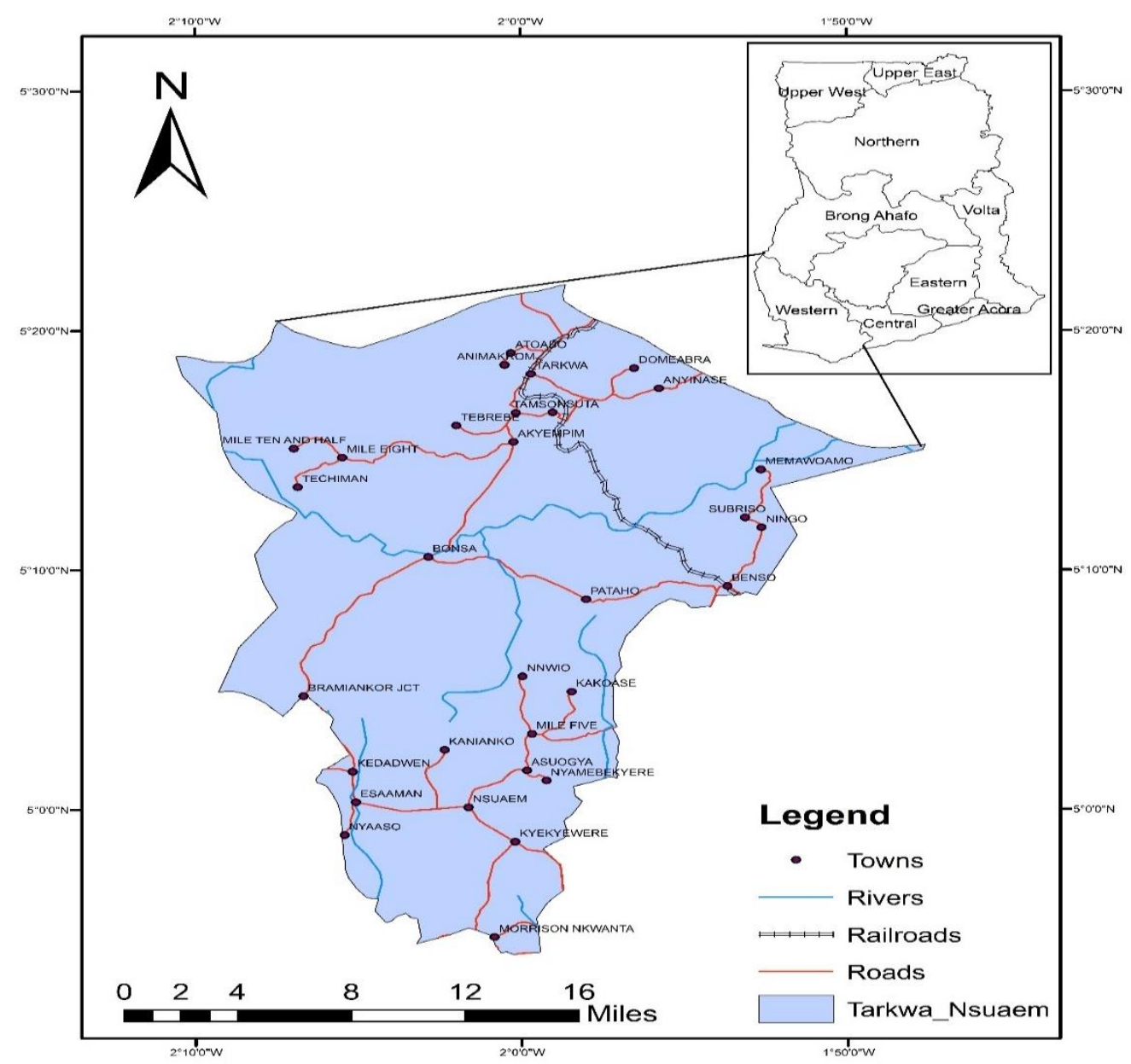

Figure 1 The Study Area

In this present study, a total of 28 Total station and GPS data was used for this present study. This data was obtained directly from field measurement and it covers some part of the University of Mines and Technology, UMaT campus. Total station and the GPS receivers' 
instruments were used for the collection of data. The Total station data was recorded in Eastings, Northings and Orthometric heights (E, N, H) whilst the GPS data was recorded in Latitude, Longitude and Ellipsoidal height $(\phi, \lambda, h)$. Table 1 is a sample of the data used to embark this present study.

Table1 Sample of Data collected from the field

\begin{tabular}{|c|c|c|c|c|}
\hline POINT ID & LATITUDE & LONGITUDE & h & H \\
\hline BM1 & 5.299648 & 2.001587 & 105.0657 & 79.2000 \\
\hline BM2 & 5.299471 & 2.001814 & 106.1565 & 80.3900 \\
\hline BM3 & 5.299346 & 2.001813 & 93.3399 & 68.4770 \\
\hline BM4 & 5.299505 & 2.001931 & 106.3422 & 80.5390 \\
\hline BM5 & 5.299301 & 2.002049 & 109.1203 & 82.4000 \\
\hline BM6 & 5.299204 & 2.002202 & 107.6099 & 81.7900 \\
\hline BM7 & 5.299211 & 2.002393 & 105.6151 & 79.7320 \\
\hline BM8 & 5.299563 & 2.001292 & 106.3142 & 80.4690 \\
\hline BM9 & 5.298738 & 2.001984 & 103.9401 & 78.1920 \\
\hline BM10 & 5.298880 & 2.002044 & 106.0406 & 80.4210 \\
\hline
\end{tabular}

\section{Methods}

\subsection{GPS/Levelling Derived Geoidal Heights}

The computation of geoidal heights from GPS observations and orthometric heights was done according to Equation 1. The geoidal heights from GPS-derived ellipsoidal heights and the Total station orthometric heights are referred to as GPS/Levelling (Dawod, 2008)).

$$
N_{\text {GPS / Levelling }}=h-H
$$


Where $\mathrm{N}_{\mathrm{GPS} / \text { Levelling }}$ is the estimated geoidal heights, $h$ is the ellipsoidal height from GPS measurements and $H$ is the orthometric height obtained from levelling procedure.

\subsection{Geoidal Heights from EGM08 Geoid Model}

The geoidal heights obtained from this model was done using the EGM08 calculator. The inputs were the geodetic coordinates and the outputs were the geodetic coordinates with their geoidal heights. The geoidal undulations computed from the EGM08 geopotential model coefficients refer to the tide-free system as far as the permanent tide is concerned (Pavlis et al., 2008). The calculated geoid heights obtained from the EGM08 model was computed based on the spherical harmonic equation (Lu et al., 2014) as denoted by Equation 2:

$V_{(p, \phi, \lambda)}=\sum_{n=0}^{\infty} \frac{1}{p^{n+1}} \sum_{k=0}^{n}\left(a_{n k} \cos k \lambda+b_{n k} \sin k \lambda\right) p_{n k}(\cos \phi)$

Where; $(p, \phi, \lambda)=$ are the spherical coordinates $a_{n k}$ and $b_{n k}=$ are the coefficients of the Earth's gravity field $p_{n k}(\cos \phi)=$ represents the associated Legendre polynomials $\mathrm{n}$ is degree, and $\mathrm{k}$ is order (Pavlis et al., 2008; Pavlis et al., 2012; Lu et al., 2014).

\subsection{Models Performance Evaluation}

In order to evaluate the adequacy of the EGM08 and the polynomial model, several statistical indicators were utilised. These include mean error (ME), root mean square error (RMSE) and standard deviation (SD). Their mathematical expressions are given in Equation 3 to 5 respectively. In computing the differences between the geoid models, the assumption made here is that, the geoidal undulations obtained from the GPS/Levelling are standard to which the geoidal heights provided by the EGM08 was compared. The geoidal undulation difference, $\Delta N$ between the GPS/Levelling geoidal undulations, $\mathrm{N}_{\mathrm{GPS} / \text { Levelling and the }}$ computed geoidal undulations referred to EGM08, $\mathrm{N}_{\mathrm{EGM} 08}$ is given as denoted by Equation 3:

$\Delta N=N_{G P S / \text { Levelling }}-N_{E G M 2008}$ 
Where $\Delta N$ is the geoidal height difference between geoidal heights obtained from geometrical techniques ( $\left.\mathrm{N}_{\mathrm{GPS} / L e v e l l i n g}\right)$ and EGM approach ( $\mathrm{N}_{\mathrm{EGM} 2008)}$

The mean difference, $\Delta N_{\text {mean }}$ is the average of the geoidal height differences, $\Delta N j$ for the EGM08 model. The mean is computed as denoted by Equation (4):

$$
\Delta N_{\text {mean }}=\frac{1}{n} \sum_{j=1}^{n} \Delta N_{j}
$$

Where $j=1,2,3, \ldots ., n$ and $i=1,2,3, \ldots ., n$.

The root mean square (RMSE) value of the differences in the model is computed from as denoted by Equation 5:

$$
R M S E=\sqrt{\frac{\sum_{j=1}^{n} \Delta N_{j}^{2}}{n}}
$$

The RMSE gives a sense of the typical size of the value.

The standard deviation from the mean of the differences (error) in geoidal undulations in the model was computed using Equation 6:

$$
S D=\sqrt{\sum_{j=1}^{n} \frac{\left(\Delta N_{j}-\Delta N_{\text {mean }}\right)^{2}}{n-1}}
$$

Where $n-1$ is the degree of freedom.

The standard deviation measures how closely the data are clustered about the mean.

\subsection{Hypothesis of the Problem}

A hypothesis is a statement about the parameters of a distribution. A test of a hypothesis is a rule that, based on the sample values, leads to a decision to accept or reject the null hypothesis. Normally, a test statistic is computed from the sample values (observations) and from the specification of the null hypothesis. If the test statistic falls within a critical region, the null hypothesis is rejected otherwise it is accepted. 
However, the null hypothesis is that the differences have a normal distribution with mean, $\varphi$ and variance $\sigma^{2}$. The sample mean, $\Delta \mathrm{N}_{\text {mean }}$ and sample variance, $S^{2}$ were tested to see if they really belong to normal distribution $\mathrm{N}(\varphi, \sigma 2)$. For statistical testing, the assumption made is that the population mean, $\varphi$ and variance, $\sigma^{2}$ are normally distributed. Thus, in order to see if the sample mean $\Delta \mathrm{N}_{\text {mean }}$ and variance $\mathrm{S}^{2}$ are within the confidence interval of the population mean, $\varphi$ and variance $\sigma^{2}$ from which the sample is drawn, the following hypothetical statistical tests was used:

$>$ Let $\mathrm{n}_{\mathrm{j}}$ be the geoid undulation differences from the recent geoid models such that $(j=1,2,3, \ldots ., n)$ with estimated statistics, $\Delta \mathrm{N}_{\text {mean }}$ and $\mathrm{S}$. Then, the sample mean $\mathrm{N}_{\text {mean }}$ has a T-distribution function given by Equation 7:

$$
\frac{\Delta N_{\text {mean }}-\varphi}{s / \sqrt{n}} t_{n-1}
$$

Where (n-1) is the degree of freedom, the equal to sign (=) indicates that the right-hand side is distributed with respect to left hand side. Thus at $95 \%$ probability level, the interval of population mean, $\varphi$ should be given as denoted by Equation 8:

$$
\Delta N_{\text {mean }}-t_{0.95}^{(n-1)} \frac{s}{\sqrt{n}} \leq \varphi \leq \Delta N_{\text {mean }}+t_{0.95}^{(n-1)} \frac{s}{\sqrt{n}}
$$

\section{Results and Discussions}

\subsection{Training Results}

The EGM08 calculator was used to compute the various Geoid heights for the study area. Three hundred and twenty-eight GPS data points within the University of Mines and Technology reference to the WGS84 ellipsoid were used for the training. The inputs were the geodetic coordinates (latitude and longitude) and the outputs were the geoid heights. An ordinary geometric mathematical approach was used to derive the Mean, the Root Mean Square and the Standard deviation were further estimated to assess the accuracy of the computed geoid heights. Table 2 is a sample of the estimated geoid heights by the EGM08 model and Table 3 present a summary of the computed geoid heights $\left(\mathrm{N}_{\mathrm{EGM} 2008}\right)$ by the EGM2008 model with their estimated Mean, Root Mean Square, and their Standard 
deviation. Figures 2 and 3 shows the mathematical statistics and analysis of the EGM2008 geoid heights.

Table 2 Sample of the estimated heights by the EGM model

\begin{tabular}{|c|c|c|c|}
\hline \multirow{2}{*}{ POINT ID } & LATITUDE & LONGITUDE & (m) \\
\hline BM1 & 5.299648 & -2.001587 & 25.8208 \\
\hline BM2 & 5.299471 & -2.001814 & 25.8202 \\
\hline BM3 & 5.299346 & -2.001813 & 25.8199 \\
\hline BM4 & 5.299505 & -2.001931 & 25.8202 \\
\hline BM5 & 5.299301 & -2.002049 & 25.8196 \\
\hline BM6 & 5.299204 & -2.002202 & 25.8193 \\
\hline BM7 & 5.299211 & -2.002393 & 25.8192 \\
\hline BM8 & 5.299563 & 2.001292 & 25.828 \\
\hline BM9 & 5.298738 & -2.001984 & \\
\hline & 5.298839 & -2.002044 & \\
\hline & & & \\
\hline & & & \\
\hline & & & \\
\hline & & & \\
\hline & & & \\
\hline & & & \\
\hline
\end{tabular}

Table 3 A summary of the computed geoid heights by the EGM08 model

\begin{tabular}{|c|c|c|c|c|c|}
\hline GEOID & MINIMUM & MAXIMUM & MEAN & RMS & SD \\
MODEL & $(\mathbf{m})$ & $(\mathbf{m})$ & $(\mathbf{m})$ & $(\mathbf{m})$ & $(\mathbf{m})$ \\
\hline EGM08 & 25.8126 & 25.8225 & 25.81895823 & 1.42561348 & 0.002519702 \\
\hline
\end{tabular}




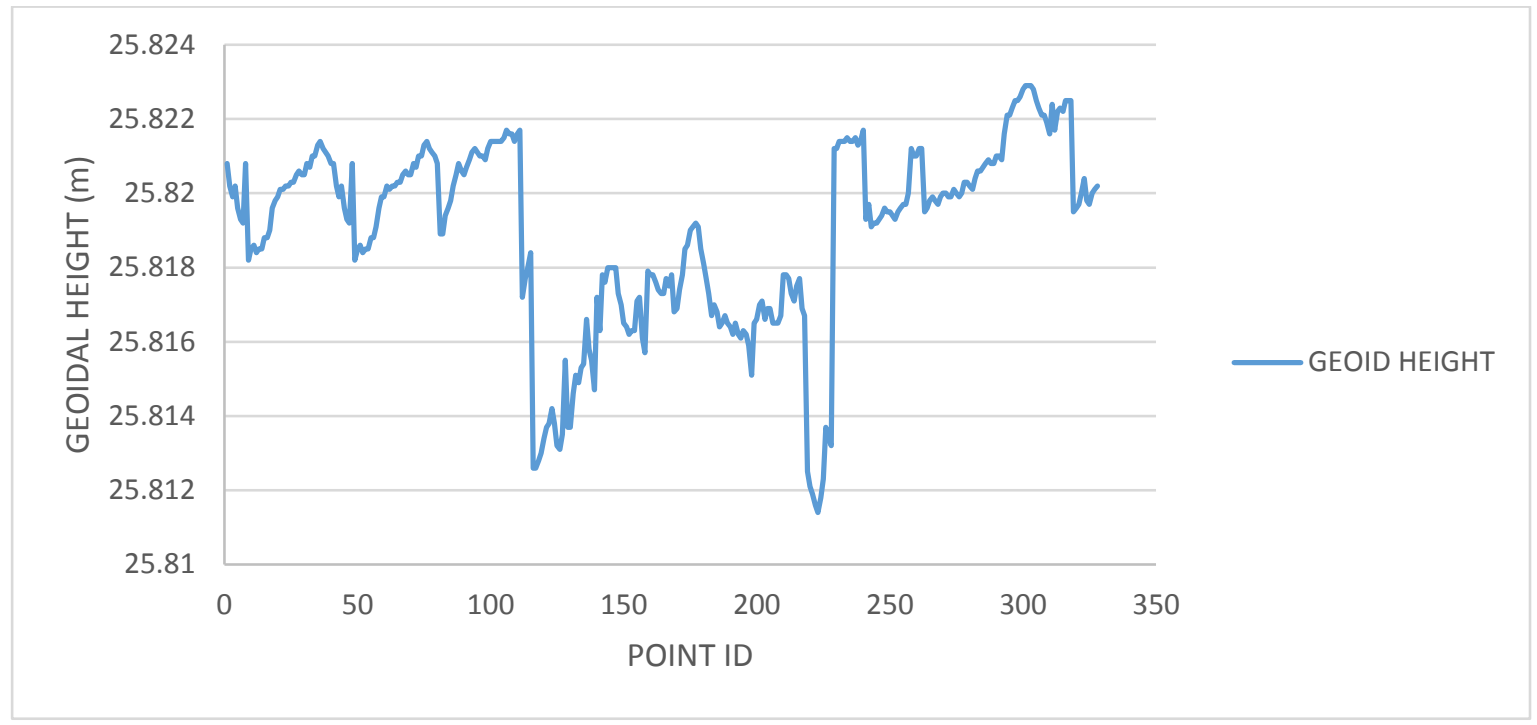

Figure 2 A graph of the EGM2008 geoidal undulations points

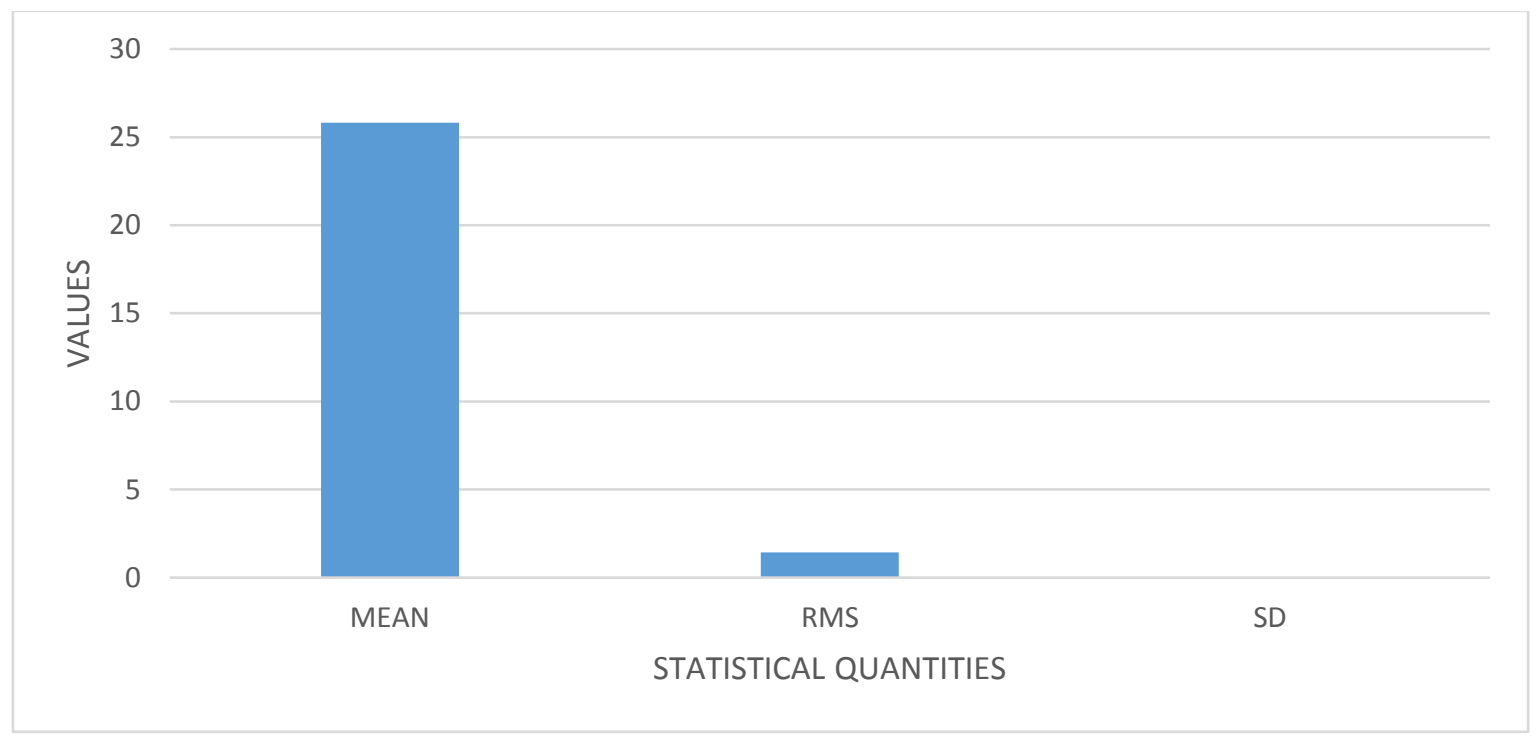

Figure 3 A graph depicting the mathematical statistics of the EGM2008 geoid height

\subsection{Testing Results}

The testing was carried out using 328 common points from the GPS and the Total station to compute the geoidal undulations of the study area. The geoidal undulations from GPSderived ellipsoidal heights and the Total station orthometric heights are referred to as GPS/Levelling. A geometric method was used to compute the Mean, the Root Mean Square, and the Standard deviation for further estimate to access the accuracy of the computed 
geoidal undulations. Table 4 presents a sample of the results of geoidal heights obtained by the geometric method ( $\mathrm{N}_{\mathrm{GPS} / \text { Levelling }}$ ) and Table 5 present a summary of the computed GPS/Levelling geoidal undulations ( $\mathrm{N}_{\mathrm{GPS} / \text { Levelling }}$ ) by an ordinary geometric approach with their estimated Mean, Root Mean Square, and their Standard deviation. Figure 4, and 5 displays the three hundred and twenty points from the Total station and the statistical graphs of the GPS/Levelling geoidal undulations.

Table 5 Sample of the results obtained by the geometric method

\begin{tabular}{|c|c|c|c|}
\hline POINT ID & h & $\mathbf{H}$ & $\begin{array}{c}\text { UNDULATION } \\
\text { (m) }\end{array}$ \\
\hline BM1 & 105.0657 & 79.2000 & 25.8657 \\
\hline BM2 & 106.1565 & 80.3900 & 25.7665 \\
\hline BM3 & 93.3399 & 68.4770 & 24.8629 \\
\hline BM4 & 106.3422 & 80.5390 & 25.8032 \\
\hline BM5 & 109.1203 & 82.4000 & 26.7203 \\
\hline BM6 & 107.6099 & 81.7900 & 25.8199 \\
\hline BM7 & 105.6151 & 79.7320 & 25.8831 \\
\hline BM8 & 106.3142 & 80.4690 & 25.8452 \\
\hline BM9 & 103.401 & 78.1920 & 25.7481 \\
\hline BM10 & 106.0406 & 80.4210 & 25.6196 \\
\hline
\end{tabular}


Table 5 A summary of the computed GPS/Levelling geoid height

\begin{tabular}{|c|c|c|c|c|c|}
\hline MODEL & MIN & MAXI & MEAN & RMS & SD \\
& $(\mathbf{m})$ & $(\mathbf{m})$ & $(\mathbf{m})$ & $(\mathbf{m})$ & $(\mathbf{m})$ \\
\hline GPS/LEVELLING & 11.1536 & 50.9063 & 27.92206474 & 1.54173811 & 3.478905399 \\
\hline
\end{tabular}

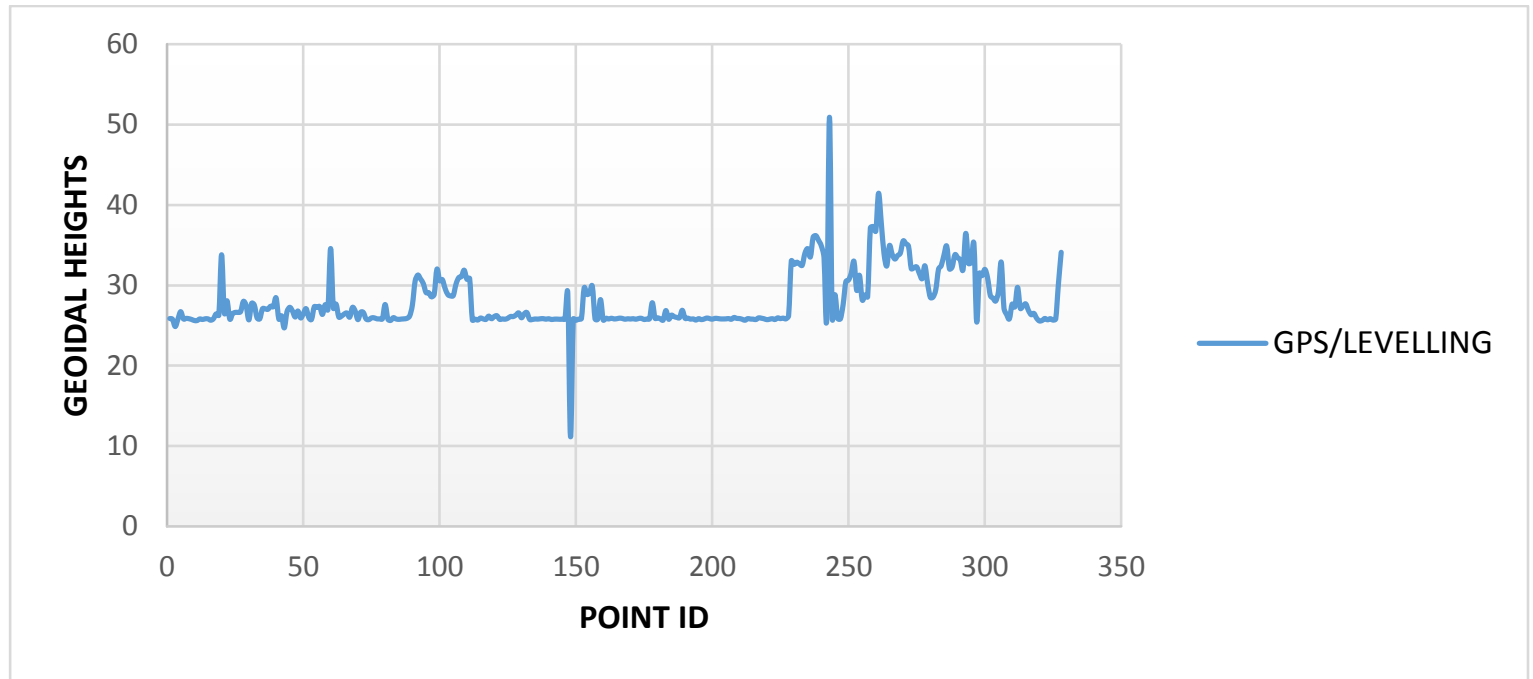

Figure 4 A graph of the GPS/levelling geoid heights

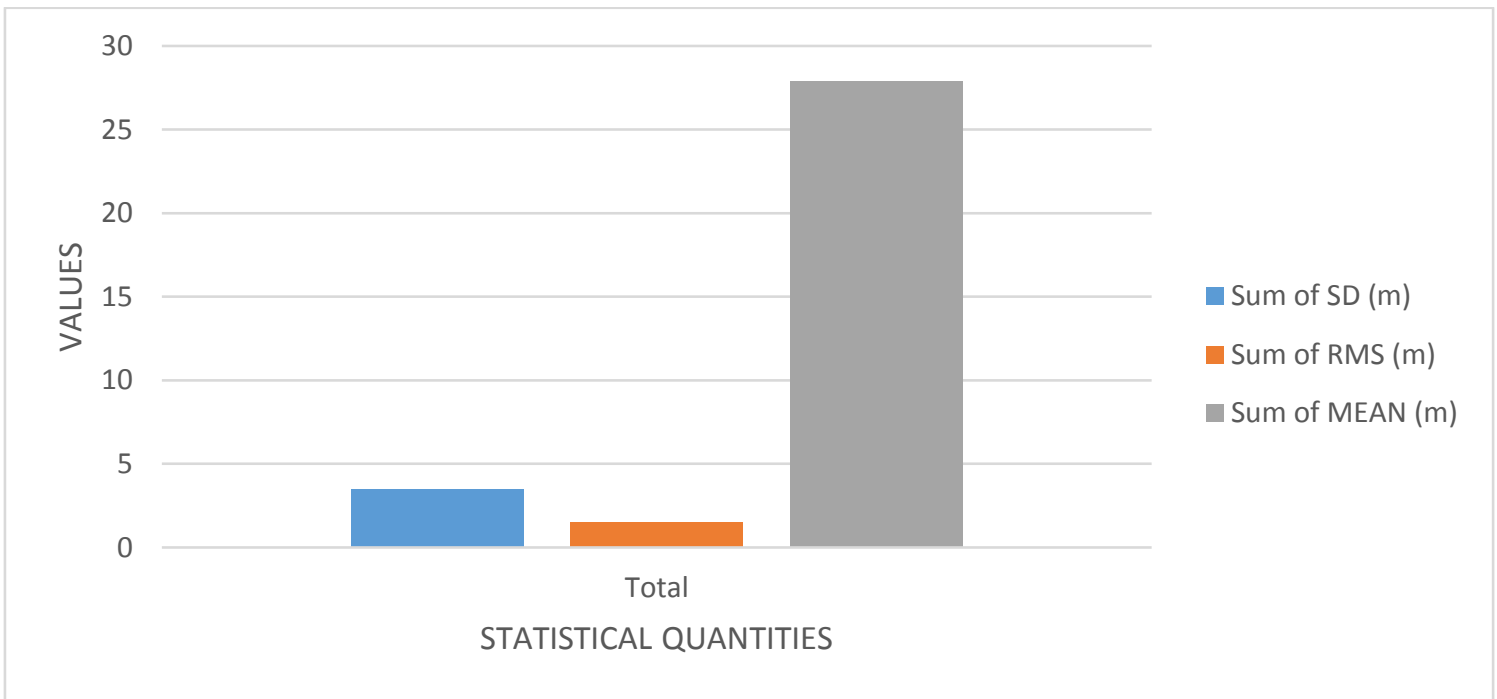

Figure 5 A graph depicting the mathematical statistics of the GPS/levelling geoid heights 


\subsection{Comparison of Geoid Heights from GPS/Levelling and the EGM2008}

The differences of geoidal heights from the GPS/Levelling derived geoidal heights and those from the geoid models at co-located benchmarks provide discrete geometric control in validation purposes. In this section, the geoidal heights differences between the geoid models against the GPS/Levelling derived geoidal heights at the 328 benchmarks were obtained. The computed geoidal heights from the GPS/levelling and the corresponding computed and predicted geoidal heights from the EGM08 are illustrated in Figure 6.

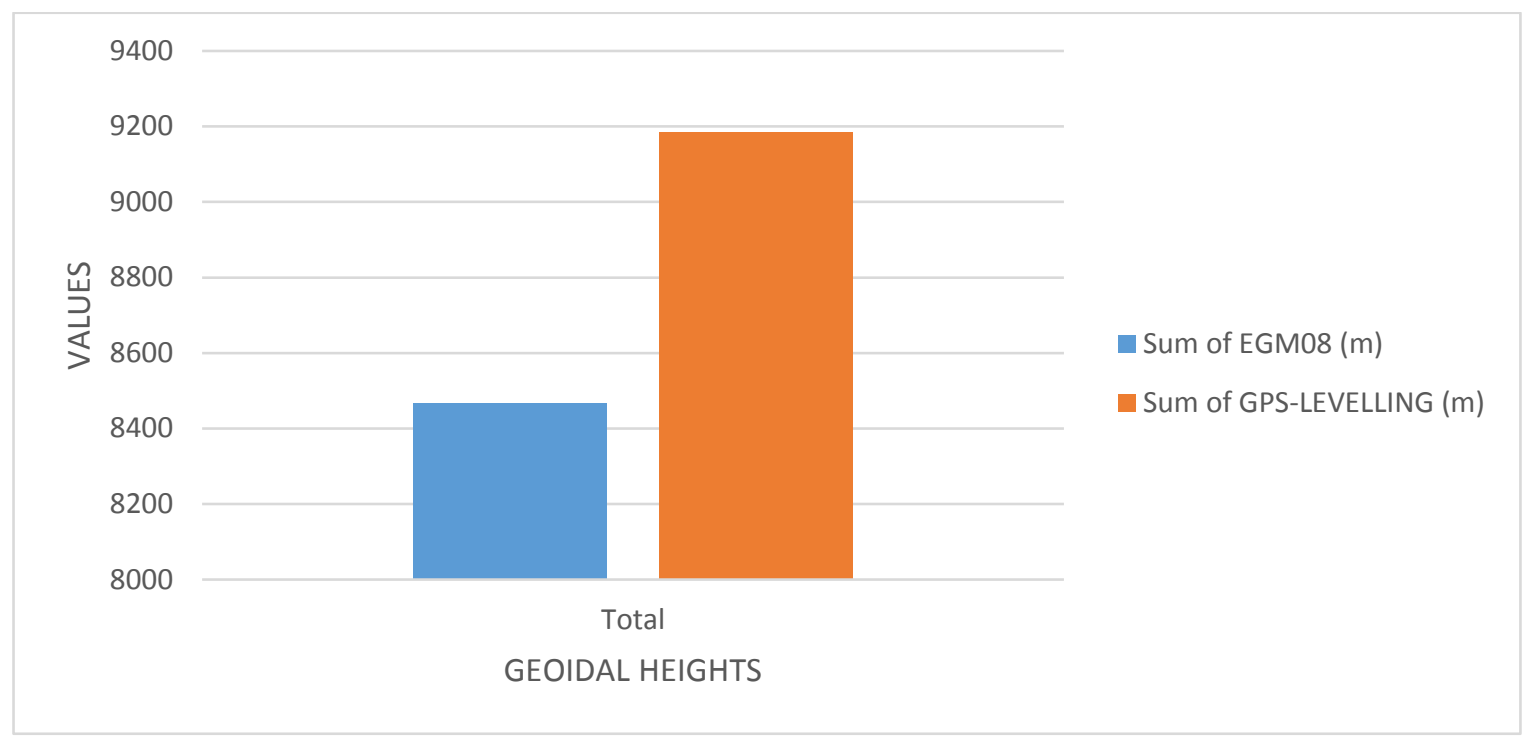

Figure 6 A graph depicting the Geoid height of EGM2008 and GPS/levelling

\subsubsection{Results from the comparison of Geoid heights from GPS/levelling and EGM2008}

Sample of the results of the geoid heights differences are tabulated in Table 6. The summary of the results obtained from the differences between the two geoidal undulations are shown in Table 7 for the recent geoid models in the area of interest. The statistics of the differences are also shown with respect to minimum differences, maximum differences, mean of the differences, root mean square of the differences and the standard deviation from the mean of the difference. Figure 7 depicts the graphs of the geoid undulation differences of the geoid model EGM2008 and the GPS/levelling. 
Table 6 Sample of the geoidal heights differences results

\begin{tabular}{|c|c|c|c|}
\hline POINT ID & $\begin{array}{c}\text { GPS/LEVELING } \\
(\mathrm{m})\end{array}$ & $\begin{array}{c}\text { EGM2008 } \\
\text { (m) }\end{array}$ & $\begin{array}{l}\mathrm{dN} \\
(\mathrm{m})\end{array}$ \\
\hline BM1 & 25.8657 & 25.8208 & 0.04490 \\
\hline BM2 & 25.7665 & 25.8202 & -0.0537 \\
\hline BM3 & 24.8629 & 25.8199 & -0.9570 \\
\hline BM4 & 25.8032 & 25.8202 & -0.0170 \\
\hline BM5 & 26.7203 & 25.8196 & 0.90070 \\
\hline BM6 & 25.8199 & 25.8193 & 0.00060 \\
\hline BM7 & 25.8831 & 25.8192 & 0.06390 \\
\hline BM8 & 25.8452 & 25.8208 & 0.02440 \\
\hline BM9 & 25.7481 & 25.8182 & -0.0701 \\
\hline BM10 & 25.6196 & 25.8185 & -0.1989 \\
\hline
\end{tabular}

Table 7 A summary of the geoid height differences

\begin{tabular}{|c|c|c|c|c|c|}
\hline HEIGHT & MINIMUM & MAXIMUM & MEAN & RMS & SD \\
& $(\mathbf{m})$ & $(\mathbf{m})$ & $(\mathbf{m})$ & $(\mathbf{m})$ & $(\mathbf{m})$ \\
\hline $\mathrm{dN}$ & -0.0012 & 25.0872 & 2.188234756 & 0.120825052 & 3.476781863 \\
\hline
\end{tabular}




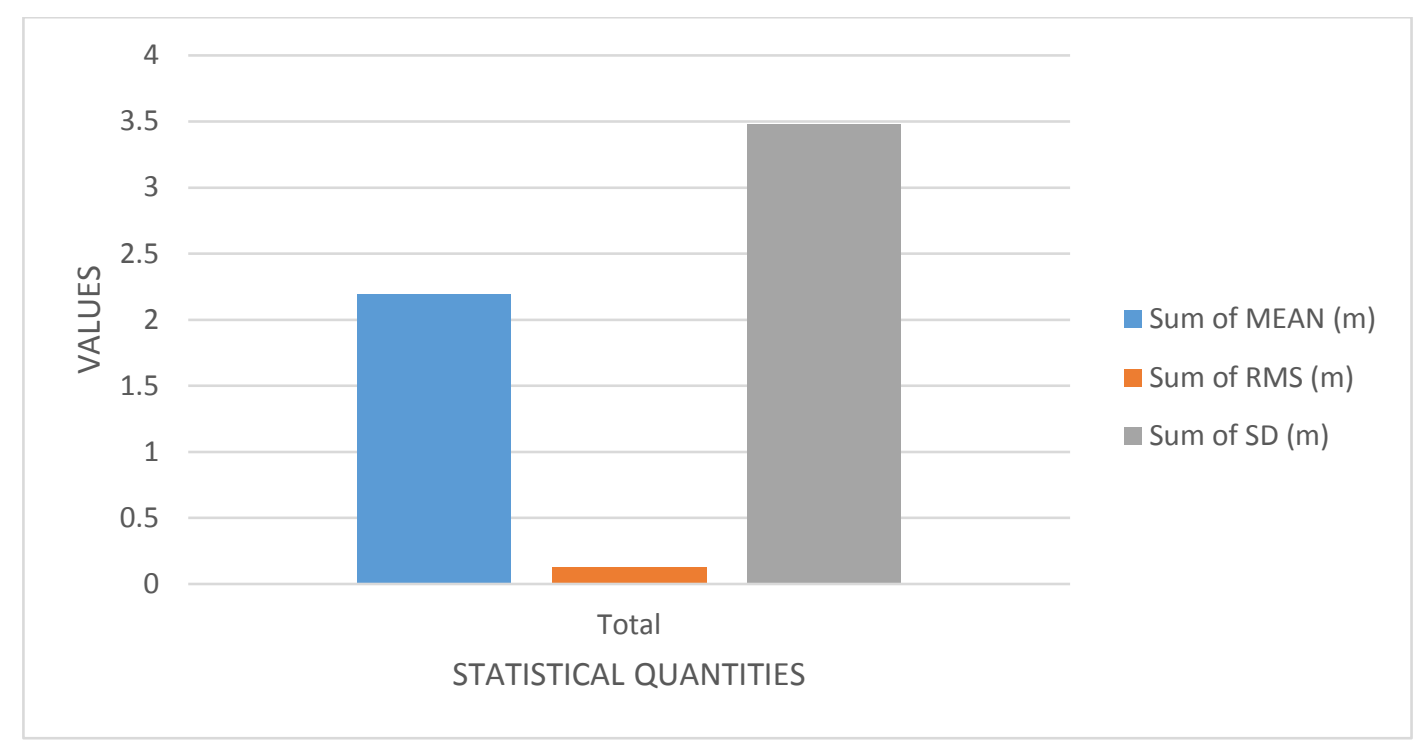

Figure 7 A graph depicting the statistics of the geoid height differences

The results obtained in this study show that there are differences between GPS/Levelling derived geoidal heights and those obtained from the New Earth Gravitational Model 2008. With reference to Table 3 and Figure 5 above, it was observed that the geoidal height differences from the GPS/levelling geoidal heights and those from the EGM2008 model ranges from $-0.0012 \mathrm{~m}$ to $25.0872 \mathrm{~m}$. The results showing the geoidal height differences are also presented graphically above. It was also seen that; the residuals range from the positive to the negative and depicting the trend of the geoid height differences from the recent geoid model based on the standard GPS/Levelling derived geoidal heights. The minimum differences are $-0.0012 \mathrm{~m}$, the maximum differences are $25.0872 \mathrm{~m}$, the mean differences are $2.18823 \mathrm{~m}$, the Root Mean Square differences are $0.12082 \mathrm{~m}$ and the standard deviation differences are $3.47678 \mathrm{~m}$. The mean differences, the Root Mean Square value and the sample Standard deviation are also represented graphically as shown in Figure 7 above.

\section{Polynomial Models Developed}

\subsection{Polynomial mathematical model}

In this project, a polynomial mathematical model was applied on the EGM2008 derived geoidal heights within the University of Mines and Technology geodetic reference network 
to improved its performance, mean square errors, root mean errors and standard deviation respectively. The general polynomial equation is given by Equation 9:

$$
Z=a_{0}+a_{1}+a_{2}+a_{3}+a_{n}
$$

The process of determining the geoidal heights and improving its performance with the polynomial mathematical model requires a lot of computational tasks which will be practically be a difficult task without the use of a computer programming language. For this task, a Microsoft Excel and Matlab 2014 software computer programming language was written to handle the geoidal heights computed and the polynomial models. The input data consist of the heights obtained from the EGM2008 calculator. The output for the polynomial mathematical model formed after determining its value were used to improve the EGM2008 geoidal heights. Three polynomial models were used for modelling the EGM08 geoid height values, the simple planar surface, the bi-linear saddle, and the quadratic surface. Their polynomial equation is given by equation (10), (11), and (12) (Soycan, 2014; Dawod et al., 2010; Dawod, 2008; Al-Kragy et al., 2014; Erol, 2011).

$$
\begin{aligned}
& N=a_{0}+a_{1} \lambda+a_{2} \phi \\
& N=a_{0}+a_{1} \lambda+a_{2} \phi+a_{3} \lambda \phi \\
& N=a_{0}+a_{1} \lambda+a_{2} \phi+a_{3} \lambda^{2}+a_{4} \lambda \phi+a_{5} \phi^{2}
\end{aligned}
$$

A Least Squares approach according to Equation 13 was used to compute the unknown parameters as denoted by:

$$
\begin{aligned}
& A X=L+V \\
& A=\left[\begin{array}{ccc}
1 & \lambda_{1} & \phi_{1} \\
\vdots & \vdots & \vdots \\
1 & \lambda_{n} & \phi_{n}
\end{array}\right] X=\left[\begin{array}{c}
a_{0} \\
\vdots \\
a_{n}
\end{array}\right] L=\left[\begin{array}{c}
d N_{1} \\
\vdots \\
d N_{n}
\end{array}\right]
\end{aligned}
$$

Where, $A=$ Matrix of coefficients for the unknown parameters, $X=$ Matrix of unknown parameters, $\mathrm{L}=$ Observation matrix; and $\mathrm{V}=$ Matrix of the residuals.

Therefore, the residuals (V) matrix is given by Equation 14:

$$
V=A X-L
$$




\subsection{Testing of the Improved EGM2008 Geoidal Heights}

The accuracies of the improved EGM2008 geoid height values were tested. In all, 328 points

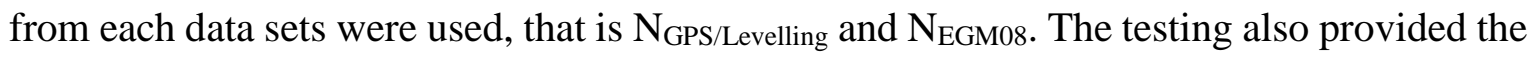
platform to know the accuracies of the two data sets when the polynomial model was applied on the EGM2008 geoid height values. This was achieved by comparing the two $\mathrm{N}$ heights. Equation 15, 16, and 17 was used to improve the new earth gravitational model.

Firstly, a trend surface is fitted to the application of method by using control points. Trend surface may be fitted by the polynomial mathematical method. According to this study, usage of the simple planar surface, bi-linear saddle, and quadratic surface polynomial functions can be sufficient in practice. Determination of the improved model was carried out through 3, 4, 6 parameter trend solution according to the polynomial order of degree.

$$
\begin{aligned}
& T_{i}=a_{0}+a_{1} \lambda+a_{2} \phi \\
& T_{i}=a_{0}+a_{1} \lambda+a_{2} \phi+a_{3} \lambda \phi \\
& T_{i}=a_{0}+a_{1} \lambda+a_{2} \phi+a_{3} \lambda^{2}+a_{4} \lambda \phi+a_{5} \phi^{2}
\end{aligned}
$$

The trend values calculated for each point the $\mathrm{dN}$ values were calculated by subtracting the geoid height differences as denoted by Equation 18 (Soycan, 2014; Dawod et al., 2010):

$d N_{i}=\Delta N_{i}-T_{i}$

Subsequently, dN values were modelled by least squares fitting with a suitable surface. For this purpose, the Matlab 2014 software algorithm was used. Thus, $\mathrm{dN}$ values were calculated for each model (Soycan, 2014).

Finally, the Improved EGM08 geoid height values at each point can be calculated by adding the trend value $(\mathrm{Ti})$, and the difference value $(\mathrm{dN})$ to known EGM2008 geoid height as denoted by Equation 19:

$$
N_{i}^{\mathrm{Im} \text { proved }}=N_{i}^{E G M 2008}+T_{i}+d N_{i}
$$

As a result, the polynomial mathematical model had a best agreement with the GPS/levelling derived geoid heights. Looking at the Figure 8 and Table 8, it is obvious that the three models improved the EGM2008 geoid heights values to equally match the GPS/Levelling geoidal height values. Thus, the results of the polynomial mathematical model have revealed that the EGM08 geoid model performs exceedingly over the study area. 
Table 8 Sample of the improved EGM geoid heights values

\begin{tabular}{|c|c|c|c|c|}
\hline & GPS/LEVELLING & MODEL A & MODEL B & MODEL C \\
\hline POINT ID & $(\mathbf{m})$ & $(\mathbf{m})$ & $(\mathbf{m})$ & $(\mathbf{m})$ \\
\hline BM1 & 25.8657 & 25.8657 & 25.8653 & 25.5000 \\
\hline BM2 & 25.7665 & 25.7665 & 25.7669 & 25.6250 \\
\hline BM3 & 24.8629 & 24.8629 & 24.8632 & 25.1250 \\
\hline BM4 & 25.8032 & 25.8032 & 25.8034 & 25.8750 \\
\hline BM5 & 26.7203 & 26.7203 & 26.7203 & 26.7500 \\
\hline BM6 & 25.8199 & 25.8199 & 25.8202 & 25.6250 \\
\hline BM7 & 25.8831 & 25.8831 & 25.8827 & 26.1250 \\
\hline BM8 & 25.8452 & 25.8452 & 25.8457 & 25.5000 \\
\hline BM9 & 25.7481 & 25.7481 & 25.7485 & 25.7500 \\
\hline BM10 & 25.6169 & 25.6169 & 25.6191 & 25.3750 \\
\hline
\end{tabular}

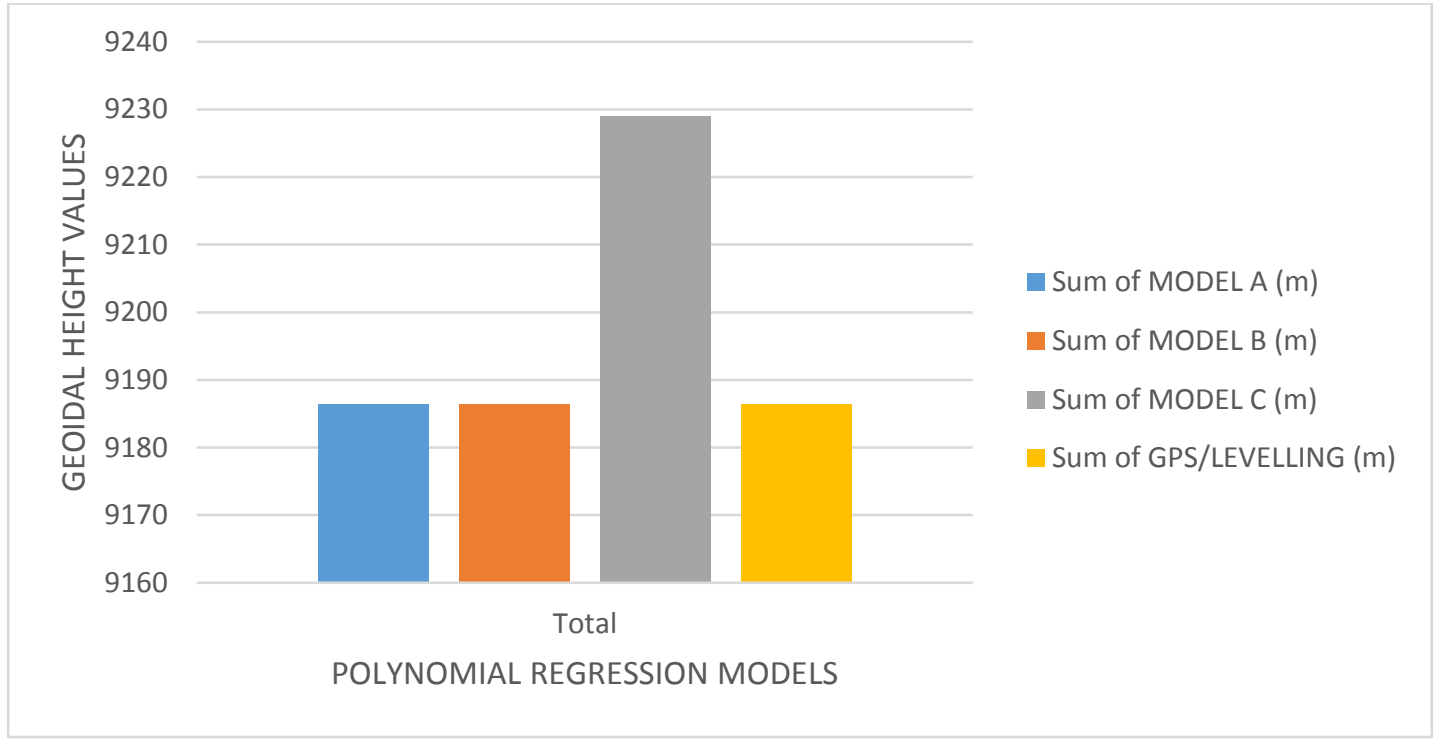

Figure 8 A graph of the various polynomial models 


\section{Hypothesis testing}

These tests were performed in order to quantify if the sample mean, $\Delta \mathrm{N}_{\text {mean }}$ and variance, $S^{2}$ are within the confidence interval of the estimate population mean, $\varphi$ and variance $\sigma^{2}$ from which the sample is drawn from the geoid model. The information which is used to find the truthiness in validating the geoid models are those found in Table 3.

Using Equation (20) the population mean, $\varphi$ can be tested as follows;

Let the null hypothesis $H_{0}: \varphi_{E G M 2008}=2.1882$

From the statistical Tables $t_{0.95}{ }^{(n-1)}=1.960, \Delta N=2.1882, \sqrt{n}=18.1108, S=3.4768$ and degree of freedom $(n-1)=327$, then the interval becomes as denoted by Equation 21 :

$1.8119 \leq \varphi_{E G M 2008} \leq 2.5645$

Equation (21) entails the acceptance of the null hypothesis in equation (20).

\section{Conclusion}

To conclude, it can be fairly stated that EGM08 approach have not been applied and tested within the Ghana local geodetic reference network for estimating geoidal heights $(\mathrm{N})$ in order to convert GPS heights $(\mathrm{h})$ to a practical height $(\mathrm{H})$. Moreover, it is well known that the accuracy of the determined local geoidal heights has an influence on the transformed GPS ellipsoidal heights to orthometric heights. Hence there is the need to investigate the efficiency and performance of the EGM08 in estimating local geoid heights within Ghana's local geodetic network. This study evaluated, compared and improved the recent geoid model (EGM08) derived geoid heights in the University of Mines and Technology, UMaT, Tarkwa using GPS/Levelling (geometric approach) derived geoidal heights as an independent tool for validation of results obtained from the geoid model (EGM08). In order to ascertain the efficiency of the EGM08, the longitude and latitude obtained from the GPS measurements were applied in the EGM08 model to estimate geoid heights to be able to convert GPS ellipsoidal heights from the World Geodetic System 1984 (WGS84) to local geodetic system (Accra datum). According to the results and the objectives of this project, the polynomial mathematical model best agree with the geometric estimated geoid heights 
(GPS/Levelling). The difference between the EGM and geometric estimated heights with mean differences of $2.18823 \mathrm{~m}$ and the RMSE of $0.1208 \mathrm{~m}$ lead to the conclusion that the EGM2008 geoid model is a better model for GPS/levelling in the study area at the moment. The accuracies of the geoid model for a local geoid scale have been assessed, it was realized from the results obtained that each polynomial model has varying degree of accuracies. Based on the results, the polynomial regression is the proposed model for a local geoid modelling in the study area. This study will therefore create the opportunity for geospatial practitioners in developing countries like Ghana to arrive at a consensus on the most appropriate alternative technique applicable for estimating local geoid heights within the local geodetic reference network. This study will also create the opportunity to know the efficiency and performance of applying EGM as a plausible practical alternative technology to the traditional geometric method in estimating geoidal heights. It could also improve the general accuracy method in topographic mapping and three-dimensional (3D) coordinate transformation.

\section{References}

Abeho, D. R., Hipkin, R. and Tulu, B. B. (2014), "Evaluation of EGM08 by means of GPS levelling Uganda", South African Journal of Geomatics, Vol. 3, No. 3, pp. 272-284.

Al-Ghamdi, K. A. and Dawod, G M. (2013), “Accuracy Assessment of Global Geopotential Models for GIS and Geomatics Applications in Makkah Metropolitan Area", Eight National GIS Symposium in Saudi Arabia, Jumala, KACST Technology Innovation Center (TIC) Geographic Information Systems, Umm Al-Qura University, Makkah, Saudi Arabia.

Al-Krargy, E. M., Doma, M. I. and Dawod, G. M. (2014), “Towards an Accurate Definition of the Local Geoid Model in Egypt using GPS/levelling Data: A Case Study of Rosetta Zone", International Journal of Innovative Science and Modern Engineering, Vol. 2 Issue 11, pp. 1-6.

Bae, T. S., Lee, J., Kwon, J. H., Hong, C. K. (2011), "Update of the precision geoid determination in Korea", Journal of Geophysical Prospecting, Vol. 60, No. 3, pp. 555571. 
Chandler, G. and Merry, C. (2010), "The South African Geoid 2010: SAGEOID 10", Journal of Position IT, pp. 29-33.

Daho, S. (2008), "New investigation on the choice of the tailored geopotential model for Algeria", Journal of Geodynamics, Vol. 45, pp. 154-162.

Dawod, G. (2008), “Towards the redefinition of the Egyptian geoid: performance analysis of recent global geoid models and digital terrain models", Journal of Spatial Science, Vol. 53, No. 1, pp. 31-42.

Dawod, G. M., Mohammed, H. F., Ismail, S.S. (2010), "Evaluation and adaptation of the EGM2008 geopotential model along the Northern Nile Valley, Egypt: Case Study", Journal of Surveying, Vol. 136, pp. 36-40.

Do, N. D. (2011), "Fitting Research about EGM2008 High Anomaly Bases on GPS/Levelling Datas in local Vietnam, Published Thesis, HA NOI University of Mining and Geology, Vietnam, $26 \mathrm{pp}$.

Dumrongchai, P. (2012), “Assessment of Gravity requirements for precise Geoid determination in Thailand", The $33^{\text {rd }}$ Asian Conference on Remote Sensing, Ambassador City Jomtien Hotel, Pattaga, Thailand, 12 pp.

Erol, B., and Erol, S. (2012), "GNSS in practical Determination of Regional Heights, Global Navigation Satellite Systems: Signal, theory and Applications, Prof. Shuanggen Jin (Ed.), ISBN: 978-953-307-843-4, InTech, Avaible from : http://www.intechopen.com/books/global-navigation-satellite-systems-signal-theoryand-applications/gnss-in-practical-determination-of-regional-heights, Accessed: October 10, 2016, 426 pp.

Erol B., (2011), “An automated height transformation using precise geoid models”, Journal of Scientific Research and Essays, Vol. 6, No. 6, pp. 1351-1363.

Featherstone, W and Vanicek, P. (1998), "The Role of Coordinate Systems, Coordinates and Heights in Horizontal Datum Transformations", Western Australian Divisions of Institution of Surveyors and Mapping Sciences, Institute and University of New South Wales. 
Featherstone, W. E., Kirby, J. F., Kearsley, A. H. W., Gilliland, J. R., Johnston, G. M., Steed, J., Forsberg, R., and Sideris, M. G. (2001), "The AUSGeoid98 geoid model of Australia: data treatment, computations and comparisons with GPS/Levelling data, Journal of Geodesy, Vol. 75, No. 5, pp. 313-330.

Featherstone, W. E. (2002), "A Simple Method to Improve the Geoid from a Global Geopotential Model (or Coarse Geoid Estimation Using only the Innermost Zone Contribution of Stokes's formula)", International Geoid Service Bulletin, Vol. 12, pp. $81-90$.

Fotopoulos, G. (2003), "An analysis on the optimal combination of geoid, orthometric and ellipsoidal height data", Published Thesis, University of Calgary, Alberta, Canada, $258 \mathrm{pp}$.

Fotopoulos, G., Kotsakis, C., and Sideris, M. G. (1999), "Evaluation of Geoid Models and their Use in Combined GPS/Levelling/Geoid Height Network Adjustments, Published Technical Reports, University of Calgary, Alberta, Canada, 72pp.

Forson, K. I. (2006), "Design of distribution network for University of Mines and Technology", Unpublished BSc Project Report, University of Mines and Technology, Tarkwa, Ghana, 10pp.

Gruber, T., Visser, P. N. A. M., Ackermann, Ch., and Hosse, M. (2011), "Validation of GOCE gravity field models by means of orbit residuals and geoid comparisons", $J$. Geod, Vol. 85, pp. 845-860.

Heiskanen, W. A., and Moritz, H. (1967), "Physical Geodesy", San Francisco, WH Freeman.

Hirt, C., Gruber, T., and Featherstone, W. E. (2011), "Evaluation of the first GOCE Static gravity field models using Terrestrial gravity, Vertical deflections and EGM2008 quasigeoid heights, Journal of Geodesy, Vol. 85, pp. 723-740.

Kotsakis, C., and Sideris, M. G. (1999), "On the Adjustment of Combined GPS/Levelling/Geoid Networks", Journal of Geodesy, Vol. 73, pp. 412-421. 
Kotsakis, C., Katsambalos, K., Ampatzidis, D. and Gianniou, M. (2009), "Evaluation of EGM2008 Using GPS and levelling Heights in Greece", www.users.auth.gr/kvek/crete-paper-2008.pdf._Accessed: October 10, 2016.

Krynski, S. and Lyszkowicz, A. (2006), "Regional quasi-geoid determination in the area of Poland", Proceeding of $5^{\text {th }}$ FIG Regional Conference, Accra, Ghana, pp. 1-17.

Kuroishi, Y., Ando,H., and Fukuda,Y. (2002), “A new hybrid geoid model for Japan, GSIGEO 2000”, J. Geod., Vol. 76, pp. 428-436.

Lee, S. and Kim, C. (2008), "Evaluation of EGM2008 earth geopotential model using GPS/levelling data", Journal of the Korean Society for Geospatial Information System, Vol. 16, pp. 117-126.

Lee, S., Kim, J., Jung, Y., Choi, J and Choi, C. (2012), "Implementation of the Distributed Parallel Program for Geoid Heights Computation using MP1 and Open MP, International Achieves of the Photogrammetry, Remote Sensing and Spatial Information Sciences, 2012 XX11 ISPRS Congress, 25 August-01 September, Melbourne, Australia, Vol. XXXIX-B4, pp. 225-229.

Lee, S., Choi, C., and Kim, J. (2013), "Evaluating the Suitability of the EGM2008 geopotential model for the Korean Peninsula using Parallel Computing on a dislike cluster”, Journal of Computer and Geosciences, pp. 132-145.

Lemoine, F. G., Smith, D. E., Kunuz, L., Smith, R., Pavlis, E. C., Pavlis, N. K., Klosko, S. M., Chinn, D. S., Torrence, M. H., Williamson, R. G., Cox, C. M., Rachlin, K. E., Wang, Y. M., Kenyon, S. C., Salman, R., Trimmer, R., Rapp, R. H., and Nerem, R. S. (1997), "The development of the NASA GSFC and NIMA joint geopotential model, in Graivty, Geoid, and Marine Geodesy”, IAG Symposia, Vol. 117, pp. 461-469.

Lerch, F. J., Nerem, R. S., Putney, B. H., Felsentreger, T. L., Sanchez, B. V., Maeshall, J. A., Klosko, S. M., Patel, G. B., Williamson, R. G., Chinn, D. S., Chan, J. C., Rachlin, K. E., Chandler, N. L., McCarthy, J. J., Luthcke, S. B., Pavlis, N. K., Pavlis, D. E., Robbins, J. W., Kapoor, S., Pavlis, E. C. (1994), “A geopotential model from Satellite tracking, altimeter, and Surface gravity data: GEM-T3”, Journal of Geophysical Research, Vol. 99, pp. 2815-2839. 
Lu, Z., Qu, Y., and Qiao, S. (2014), "Geodesy: Introduction to Geodetic Datum and Geodetic Systems", Springer Heidelberg NewYork Dordrecht, London, 417pp.

Merry, C. L., Blitzkow, D., Abd-Elmotaal, H., Fashir, H. H., John, S., Podmore, F., and Fairhead, J. D. (2005), “A preliminary geoid model for Africa In: A Window on the future of Geodesy", (Ed: Sanso, F.), Springer, Berlin.

Olliver, J. G. (2007), “The gravimetric Geoid model of Tanzania”, Survey Review, Vol. 39, No. 305, pp. 212-225.

Parker, A., Merry, C. L., Combrinck, W. L., Combrink, A., and Wonnacott, R. T. (2007), "Review of recent Research in geodesy in South Africa; 2003-2006", Proceedings of the IUGG General Assembly in Perugia, Italy.

Pavlis, N. K., Holmes, S. A., Kenyon, S. C. and Factor, J. K. (2008), “An Earth Gravitational Model to Degree 2160", EGU General Assembly 2008, Vienna, Australia, pp. 13-18.

Rapp, R. H., Wang, Y. M., Pavlis, N. K. (1991), “The Ohio State 1991 Geopotential and sea surface Topography Harmonic Coefficient Models, Report No. 410, Department of Geodetic Science and Surveying, The Ohio State University, Columbus, 94pp.

Rapp, R. H., and Wang, Y. M. (1993), “Geoid undulation differences between Geopotential models", Surveys in Geophysics, Vol. 14, pp. 373-380.

Roman, D.R., Wang, Y. M., Saleh, J. and Li, X. (2009), "National Geoid Height Models for the United States: USGG2009 and GEOID09, ACSM-MARLS-UCCS-WEPS Conference 2009, Salt Lake City, UT USA.

Seidu, M. (2004), "GIS as a Tool in Water Monitoring for Public Health and Safety Management", Unpublished BSc Report, University of Mines and Technology (UMaT), Tarkwa, Ghana, 6pp.

Shen, W., and Han, J, (2013), "Improved Geoid Determination Based on the Shallow-Layer Method: A Case Study Using EGM2008 and CRUST2.0 in the Xinjiang and Tibetan Regions", Terr. Atmos. Ocean. Sci, Vol. 24 , No. 4, pp. 591-604.

Soycan, M. (2014), "Determination of Geoid Heights by GPS and Precise Trigonometric levelling, Survey Review, Vol. 38, No. 299, pp. 387-396. 
Tapley, B., Ries, S., Bettadpur, D., Chambers, M., Chang, F., Condi, B., Gunter, Z., Kang, P., Nagel, R., Pastor, T., Pekker, Poole, S., and Wang, F. (2005), “GGMOZC-An Improved Earth gravity field model from GRACE, J Geod, Vol. 79, pp. 467-478.

Toth, G. Y., Rozsa, S. Z., Andritsans, V. D., Adam, A. and Tziavis, I. N. (2000), “Towards a cm-geoid for Hungary: recent efforts and results", Journal of Physics and Chemistry of the Earth, Vol. 25, pp. 47-52.

Ulotu, P. E. (2009), “ Geoid Model of Tanzania from Sparse and Varying Gravity Data Density by the KTH Method”, Published PhD Thesis, Royal Institute of Technology (KTH), 10044 Stockholm, Sweden, 204pp.

Yilmaz, I., Yilma, M., Gullu, M., and Turgut, B. (2010), "Evaluation of recent global geopotential models based on GPS/Levelling data over Afyonkarahisar (Turkey), Scientific Research and Essays, Vol. 5, No. 5, pp. 484-493.

Ziggah Y. Y. (2012), "Regression Models for 2-Dimensional Cartesian Coordinates Prediction: A Case Study at University of Mines and Technology (UMaT)”, International Journal of Computer Science and Engineering Survey (ISCSES), Vol. 3, No. 6, 62pp.

Ziggah, Y. Y. (2014), "Principles of Geodesy". Unpublished BSc Lecture Notes, University of Mines and Technology, Tarkwa, Ghana, 176pp. 